\title{
Corrigendum \\ Peripheral BDNF Produces Antidepressant-Like Effects in Cellular and Behavioral Models
}

\section{Heath D Schmidt and Ronald S Duman}

Neuropsychopharmacology (20I I) 36, 550; doi:10.1038/npp.2010.205; published online 17 November 2010

Correction to: Neuropsychopharmacology (2010) 35, 2378-2391; doi:10.1038/npp.2010.114; published online 4 August 2010
In this article, the authors have identified an error in Figure 5. Please see the revised Figure 5 below.

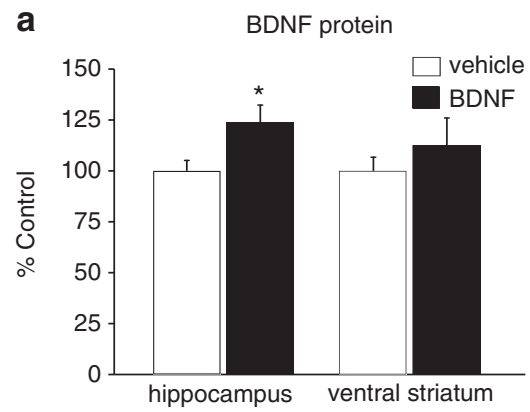

b

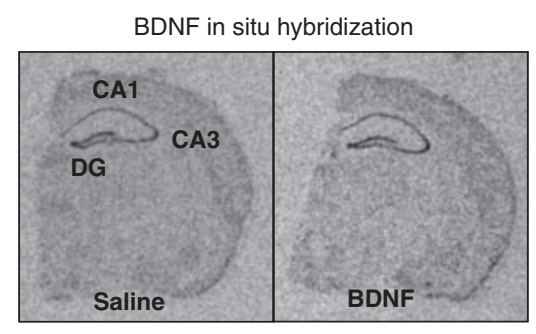

C

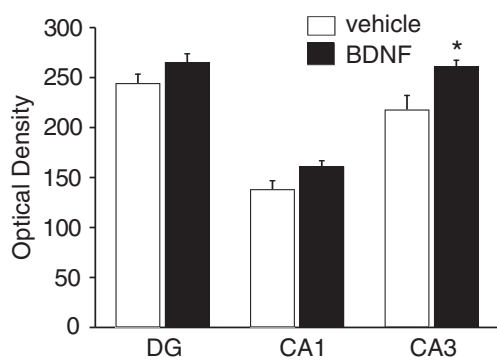

